\title{
Abandono por inasistencia a las audiencias en el sistema procesal oral reguladas por el COGEP
}

\author{
Abandonment due to non-attendance at hearings in the oral procedural system \\ regulated by COGEP
}

\section{Abandono por não comparecimento a audiências no sistema de procedimento oral regulado pela COGEP}

Ana María Miranda Sánchez

abganamaria@hotmail.com

https://orcid.org/0000-0002-5042-5774

Universidad Regional Autónoma de los Andes "UNIANDES", Ecuador

\author{
Edison Manuel Pozo Calderon \\ emanuelpozoc@hotmail.com \\ https://orcid.org/0000-0002-0909-693X \\ Universidad Regional Autónoma de los Andes \\ "UNIANDES", Ecuador
}

Artículo recibido en julio 2020 | Arbitraje en agosto 2020 | Aceptación en septiembre 2020 | Publicación en octubre 2020

RESUMEN

ABSTRACT

RESUMO
El objetivo de la investigación fue proponer un anteproyecto de ley reformatoria al COGEP, sobre la declaratoria de abandono a las audiencias para garantizar los derechos personales y patrimoniales del accionante. La metodología fue de tipo descriptiva- propositivo, bajo un enfoque mixto, y un diseño documental de campo, a su vez, se utilizaron los métodos sistemático, deductivo, inductivo e histórico-lógico. La técnica e instrumento empleados fueron la observación y la encuesta (cuestionario). La población estuvo conformada por 2705, abogados en libre ejercicio de la Provincia de Tungurahua y la muestra utilizada fue de 96. Se obtuvo como resultado, que existe mucha inconformidad con lo que estipula el COGEP, en relación al abandono de la acción por vulnerar el derecho a la igualdad. De esta manera, se concluye que la propuesta está encaminada a que al accionante se le permita justificar la inasistencia a las Audiencias.

Palabras clave: COGEP; audiencia; derecho comparado; abandono procesal, oralidad

The objective of the investigation was to propose a draft reform law to COGEP, on the declaration of abandonment to the hearings to guarantee the personal and patrimonial rights of the plaintiff. The methodology was descriptive-propositional, under a mixed approach, and a documentary field design, in turn, the systematic, deductive, inductive and historical-logical methods were used. The technique and instrument used were observation and survey (questionnaire). The population was made up of 2705, lawyers in free practice of the Province of Tungurahua and the sample used was 96. As a result, it was obtained that there is much disagreement with what the COGEP stipulates, in relation to the abandonment of the action for violating the Equality right. In this way, it is concluded that the proposal is aimed at allowing the plaintiff to justify the absence from the hearings.

Key words: COGEP; audience; comparative law; procedural abandonment, orality

O objetivo da investigação foi propor à COGEP um projeto de lei de reforma, sobre a declaração de abandono às audiências para garantia dos direitos pessoais e patrimoniais do autor. A metodologia foi descritivaproposicional, sob abordagem mista, e de campo documental, por sua vez, foram utilizados os métodos sistemático, dedutivo, indutivo e histórico-lógico. A técnica e o instrumento utilizados foram observação e levantamento (questionário). A população foi composta por 2.705 advogados em exercício da Província de Tungurahua e a amostra utilizada foi de 96 . Como resultado, obteve-se que há muita divergência com o que estipula a COGEP, em relação à desistência da ação. por violar o direito à igualdade. Desta forma, conclui-se que a proposta visa permitir ao autor justificar a ausência das audiências.

Palavras-chave: COGEP; público; lei comparativa; abandono processual, oralidade 
En el proceso Civil el sistema oral tuvo su inicio desde tiempos históricos, pues al existir demasiada complicación ya no era necesario mantener las actuaciones para nuevos exámenes por no haber la apelación.

Tomando en referencia el pueblo hebreo, se eligió en Israel a personas enérgicas a los cuales se les dio su nombramiento como jefes del pueblo de los cuales los asuntos difíciles se los llevaba a Moisés y solucionando los más fáciles quienes eran elegidos como representantes del pueblo. Desde ese entonces existía el sistema oral público que se basaba para la administración de justicia en aspectos religiosos y sobre todo en las tradiciones de cada pueblo. (Fernández, 2014).

Una de las principales características es que la oralidad permite la reducción de tiempo y costos ya que, de alguna manera, el trabajo de acumulación de expedientes se disminuye a quien tiene que dar la solución de conflictos garantizando una investigación forense y científica. En Grecia fue donde se realizaban juicios orales y se encontraba integrado el Tribunal de Atenas, las Audiencias eran dirigidas por los jueces a quienes denominaban heliastas. (Zabaleta, 2017).

Los procedimientos civiles romanos fueron tres los fundamentales el de las acciones de la ley, el formulario y el extraordinario. El de las acciones de la ley era propiamente oral predominaba la celeridad y la actuación de las partes procesales, la valoración de la prueba, lo más esencial del procedimiento, pues se exponían las estrategias verbalmente y se acudían donde oradores o advocatus (actualmente llamados abogados) y el sistema utilizado era netamente oral. (Casanueva, 2014).

Al caer el Imperio Romano la escuela judicial de Bolonia y su influencia canónica italiana, el derecho se lo mantenía oculto de todas las formas y pasos de un procedimiento, siendo las Audiencias privadas para dictar sentencias favorables a situaciones políticas, de modo que la iglesia católica nobles como Reyes Emperadores y Monarcas no practicaban los procesos orales sino el sistema escrito. (Dal Ri, 2016).

Por medio de la Revolución Francesa y la existencia del Código Napoleón tuvo su auge el procedimiento civil, donde predominaba la publicidad de los procesos más que el sistema escrito, en el cual todo ciudadano tenía conocimiento y seguimiento de un proceso y sobre todo el contacto directo del Juez con las partes mediante las Audiencias.

Para Barrando y Odette (2013); el juicio oral es aquel que:

Se sustancia en sus partes principales de viva voz y ante el juez o tribunal que entiende en el litigio. En el juicio oral, las pruebas y los alegatos de las partes se efectúan ante el juzgador. La oralidad es esencial para cumplir con el principio de inmediación. También se define a la Oralidad como un sistema que tiende a ofrecer economía seguridad, agilidad en la recolección de pruebas como la 
intervención de las partes, a la vez permite la combinación y la expresión oral con la escrita, también determina no solo la manera de cómo el desenvolvimiento del proceso, sino la actuación de las partes procesales (s.n.).

En Ecuador se iniciaron las primeras normas jurídicas y civiles, posterior a su creación como Estado después de 1835, tras la caída de la Gran Colombia (1830). Estas primeras normas sufrieron diversas reformas y modificaciones.

Ya para el presente se crea el Código Orgánico General de Procesos, mejor conocido por su abreviatura COGEP, el cual es el cuerpo legal ecuatoriano que regula el procedimiento en los procesos judiciales entre partes que corresponden a los juzgados, salas y tribunales de justicia de Ecuador.

Fue aprobado el 26 de abril del 2015 por la Asamblea General, y fue remitido al ejecutivo para su sanción u objeción. Tres días después, el 29 de mayo se conoció la objeción parcial de presidente de la República sobre el texto aprobado inicialmente por el órgano legislativo. La Asamblea se pronunció sobre las objeciones hechas por el ejecutivo el 12 de mayo y finalmente fue publicado en el Registro Oficial el 22 de mayo.

Este código reemplazó al Código de Procedimiento Civil, reformando el proceso escrito por uno oral, lo que reduce los tiempos de demora de los juicios civiles. Por lo que genera un inconveniente como lo es, el abandono de la acción por la inasistencia del accionante a las Audiencias con el nuevo procedimiento del Código Orgánico General de Procesos, vulnerando los derechos personales y patrimoniales del accionante.

Estas desventajas ocasionadas por la aplicación precaria de la oralidad, no solo son confesadas por la doctrina procesal antigua moderna, sino que se hacen sentir en los principales fallos de los tribunales cuya jurisprudencia uniforme la reconoce expresamente.

Por consiguiente, esta norma jurídica atenta contra el principio de igualdad contenido en el número 4 del Art.66 de la Constitución de la República de Ecuador (1998), que le entrega a todos los ecuatorianos el derecho a la igualdad formal material y no discriminación, la igualdad formal se traduce en el derecho de igualdad ante la ley, mientras que la igualdad material se traduce en el derecho de igualdad en la ley, ergo, podemos afirmar que el COGEP al declarar el abandono por inasistencia a las Audiencias por el accionante atenta contra el derecho a la igualdad material porque se establece una discriminación y una desigualdad en la ley, cuando por principio todas las personas somos iguales ante la ley.

En este sentido, la investigación tuvo por objetivo general proponer un anteproyecto de ley reformatoria al COGEP, sobre la declaratoria de abandono a las audiencias para garantizar los derechos personales y patrimoniales del accionante.

Con la elaboración de un anteproyecto de ley reformatoria al COGEP, sobre la declaratoria de abandono por inasistencia a las audiencias se garantizará los derechos personales y patrimoniales del accionante, ya que la Constitución ecuatoriana por ser garantista de los derechos de los ciudadanos, protege el principio de igualdad, establecido en el artículo 11 
numeral 2 de la Carta Magna, y el mismo debe ser cumplido a cabalidad, el cual no permitirá vulneración de ningún tipo de derechos sean los mismos personales y patrimoniales, dado a que tienen una jerarquía internacional.

\section{Sistema oral procesal}

El sistema procesal Oral, se lo define como un medio de comunicación de las partes en el cual la cualidad más importante se sustenta en el uso de la palabra dejando a un lado el uso de la escritura. El sistema oral se encarga de llegar a una solución más eficaz, de las contiendas legales y una aproximación más cercana del procedimiento escrito.

Torres (2014) señala que, uno de los aspectos más esenciales es la publicidad, debido a que los ciudadanos toman acceso directamente al momento del juicio y especialmente a la intervención de todos los profesionales, jueces, abogados, defensores públicos, testigos y peritos, a la vez permite conocer la fundamentación legal de la sentencia.

Por lo tanto, Barrando y Odete (2013) define el juicio oral como aquel que se sustancia en sus partes principales de viva voz y ante el juez o tribunal que entiende en el litigio. En el juicio oral, las pruebas y los alegatos de las partes se efectúan ante el juzgador. La oralidad es esencial para cumplir con el principio de inmediación. También se define a la oralidad como un sistema que tiende a ofrecer economía, seguridad, y agilidad en la recolección de pruebas como la intervención de las partes, a la vez permite la combinación y la expresión oral con la escrita, también determina no solo la manera de cómo el desenvolvimiento del proceso, sino la actuación de las partes procesales.

\section{El sistema procesal oral en el Ecuador}

El procedimiento oral en el Ecuador sus orígenes en base al derecho romano, tomando en cuenta que para su surgimiento debía dividirse en etapas entre las principales desde el siglo III DC. Siendo un sistema de justicia privada doble prevalecía la oralidad y la también se dio gran importancia a los escritos en lo referente a la documentación que se presentaba.

Este sistema dentro de la segunda etapa del derecho romano el procedimiento privado fue cambiado por el procedimiento oficial extraordinario, en donde se utilizaba el sistema escrito y reservado sobre el sistema oral.

Más adelante en épocas antiguas se ponía énfasis al sistema escrito, en el caso de Ecuador con la Constitución de Montecristi, se dio un gran cambio al sistema oral donde lo escrito no es lo primordial, y el sistema de oralidad aparece en todos los procedimientos y materias, que describe el Código Orgánico General de Procesos. (Mejía, 2017). 


\section{Oralidad en Ecuador}

En Ecuador una vez constituido como República el 23 de septiembre de 1830, surge una normativa procesal civil, apareciendo la ley de procedimiento civil, aprobada por el Congreso Nacional el 8 de noviembre de 1831 y publicada en el primer Registro Autentico Nacional n²8, año de 1831, en la Presidencia de Juan José Flores. La segunda ley procesal civil fue dictada por la Convención del Ecuador el 15 de agosto de 1835 en la presidencia de Vicente Rocafuerte.

Dentro de la Constitución ecuatoriana desde octubre del 2008, en su artículo 86 numeral 2 que habla sobre las garantías constitucionales, establece el procedimiento oral dentro de todas las fases e instancias jurídicas de defensa.

Al analizar el artículo 168 numeral 6 de la misma Constitución de la República del Ecuador, también dispone que, en todas las materias, las etapas las diligencias sean por medio del procedimiento oral, aplicando los principios de concentración, contradicción y dispositivo. Con los inicios del sistema oral y encontrándose en la Constitución ecuatoriana se sintió la necesidad de crear de un código que regule un procedimiento oral en el Ecuador, por lo tanto se crea el Código Orgánico General de Procesos denominado COGEP, cuya finalidad es reducir la demora que originó el sistema escrito, para acelerar los procesos, por cuanto la Carta Maga constitucional del Ecuador en base las garantías jurisdiccionales de las personas a través de un sistema rápido y eficaz que permita la solución de conflictos. (Mejía, 2017).

\section{La oralidad como principio constitucional}

La oralidad integra muchos principios procesales entre los más destacados encontramos: la contradicción, inmediación y concentración, permitiendo al administrador de justicia tener un criterio valorado de conformidad a las exposiciones verbales de las partes, por lo tanto, el sistema oral en el Ecuador, a más de haberse desarrollado un sistema oral y escrito, permite una evolución en la administración de justicia ecuatoriana (Mejía, 2017).

\section{Legislación comparada}

\section{Oralidad procesal civil en Colombia}

El Derecho procesal colombiano ha tenido una serie de cambios el Sistema Oral, prevaleciendo los principios de transparencia y publicidad, el control de la actividad del Juez y de las partes, y la concentración de los actos procedimentales. Se rige por medio de los tratados Internacionales, sobre las garantías consagradas en el artículo 10 de la Declaración Universal de los Derechos Humanos y el artículo 8 de la Convención Americana de los Derechos Humanos o Pacto de San José de Costa Rica, cuyo derecho fundamental es ser escuchado públicamente. 
La oralidad en los procesos civiles colombianos se rige en un sistema mixto, en que la primera etapa se presenta de forma escrita y el resto del proceso se desarrolla de una forma oral, procurando que se realicen el menor número y el Juzgado de Audiencias, basados en el principio de contradicción, sin aplazar las diligencias procesales a lo estrictamente necesario. La carga de la prueba corresponde a los sujetos procesales, quien alega hechos, debe probarlos, y el Juez está en la obligación de resolver en base a lo probado dentro de la etapa de juicio (Rodríguez, 2010).

\section{Oralidad Procesal en Chile}

Para Núñez (2005), el sistema procesal chileno tiene como antecedente el modelo de la ley de enjuiciamiento civil española de 1855, existe un principio en que el juez conduce el proceso de manera muy pasible y lo mismo en la situación probatoria, que terminada la misma por iniciativa el juzgador, y concluida la tramitación se procede a resolver.

En el proceso oral lleva a la continuidad y a la concentración de actuaciones, ya que el desarrollo de las mismas debe realizarse sin interrupciones en el juicio oral, teniendo una gran importancia el principio de publicidad estrechamente relacionado con la oralidad, le permite al ciudadano que su causa se ponga en vista pública y se observe claramente cómo se gestiona el sistema de justicia en un estado de Derecho.

\section{Oralidad Procesal en Venezuela}

La Oralidad en los Procesos jurídicos venezolanos tuvo su origen en el Derecho Romano, siendo el fundamento en el Derecho Canónico y de una gran parte del sistema legal de los países europeos. En Venezuela de acuerdo con las exigencias de otros países ha venido imponiendo su sistema oral en el año de 1987 en la Reforma del Código de Procedimiento Civil que lo consagra en el Título XI, Capítulos I, II, III, IV, que trata de los procedimientos especiales.

El Procedimiento Oral en el Proceso Civil Venezolano tiene un vital interés, ya que no solo acelera el procedimiento sino otorga de mayor simplicidad, en el cual el legislador introduce el juicio oral abandonado el proceso escrito, y optó en mantener la oralidad en determinadas materias para asegurar el principio de concentración e inmediación, en el cual prevalece la audiencia como la parte central del procedimiento y donde se desarrolla toda la aportación probatoria para que el juez tienda a dar su resolución (Coronado, 2008).

\section{Audiencias}

El término audiencia significa escuchar a las personas que exponen o reclaman algún asunto determinado, ante las autoridades. El sistema de la audiencia pública está incorporado en las garantías constitucionales, especialmente del derecho a la defensa, que en todo procedimiento 
es el medio que tienen las partes procesales y especialmente el interesado de ser escuchado, sobre sus pretensiones por las cuales ha iniciado una contienda legal, ya que, al cumplirse este acto oral de ser oído, pueda dictarse una sentencia porque hizo uso de su derecho de expresión. (Fonrouge, 1996).

A su vez, las audiencias tienen dos características: 1) la publicidad y transparencia que conlleva todo el procedimiento y 2) acceso y participación a través de la oralidad y público que todos los interesados puedan acceder al procedimiento (Fonrouge, 1996).

\section{Sistema de Oralidad por Audiencias}

El proceso civil oral audiencias es el indicado para que el juez pueda utilizar la sana crítica, conlleva al juez a que pueda dirigir el procedimiento con mayor agilidad desde que el interesado propone la acción legal hasta que se dicte sentencia.

El juez pone a conocimiento y en contacto de las partes el material de la causa de tal forma que puede resolver las dudas de los intervinientes y a la vez puede indicar que falencias han incurrido las partes.

Al practicarse normalmente las pruebas, ante el juez conocedor de la causa, garantiza que el proceso se resuelva de una manera segura y prudente, en vista de que existe reunión entre autoridad judicial y las partes, en el momento del debate de actor y demandado, quienes son conocedores del pleito que propusieron todos sus argumentos, permite al juzgador en caso de alguna duda que tuviere los intervinientes, resolverla por encontrarse en contacto directo con los mismos (Nieva, 2010).

\section{Abandono Procesal}

El abandono consiste en el efecto de dejar o aislar personas o cosas, que comprende derechos y obligaciones, pero hay una excepción en lo que refiere a derechos que por su naturaleza son irrenunciables, que puede ocasionar sanciones penales o civiles en contra del abandonante, la gran diferencia radica cuando se trata de derechos o cosas que no son irrenunciables (Ossorio, 2006).

Alessandri (1950) define el abandono procesal como, la pérdida de procedimiento iniciado, por no haberse hecho gestión alguna en el pleito por ninguna de las partes durante cierto plazo. El abandono de la instancia solo produce la pérdida del procedimiento, pero no extingue las acciones y excepciones de las partes, como ocurre con el desistimiento de la demanda. 
En este sentido, el autor manifiesta que el abandono es considerado cuando se deja de seguir un trámite que ya ha tenido su inicio, dejando de realizar las gestiones en las causas por ninguno de los sujetos procesales dentro de un determinado tiempo, se menciona el abandono de instancia en el cual se refiere solo a la pérdida de consecución de la causa, lo que no extingue las acciones y excepciones propuestas como se da con el desistimiento de una demanda.

Por otro lado, Maurino (1991) define el abandono como una institución jurídica que extingue la relación procesal en el estado en que se encuentre, por inactividad de las partes y del Juez que no realizan actos de prosecución de la instancia, cuyo efecto es que pone fin al proceso sin afectar la pretensión.

El autor manifiesta el Abandono como una institución jurídica que deja sin efecto el trámite procesal, debido a que las partes no han continuado el mismo y también el Juez no ha realizado ninguna acción para que la causa se active, sin embargo, el efecto que se produce es poner fin al proceso si perjudicar su reclamación.

De esta manera, se puede decir que el abandono no es más que dejar de proseguir la acción legal por un determinado tiempo sin que las partes procesales hayan impulsado el mismo produciendo como efecto poner fin al mismo.

\section{El abandono en el Código Orgánico General de Procesos}

El Código de Procedimiento Civil en Ecuador fue creado para regular la tramitación de proceso escrito, la carga procesal no era tan alta como la actual, de tal modo que el sistema escrito era muy factible.

Conforme la sociedad ha ido evolucionando, se volvió necesario el cambio de un sistema escriturario al sistema oral, es decir un cuerpo normativo que mejore las necesidades de las personas y mejorar el sistema de justicia en el Ecuador, creándose el Código Orgánico General de Procesos, que es un cambio total, lo cual se vio en tratar de evitar la carga procesal de las Unidades Judiciales que estas tienen.

\section{Consecuencias legales de la declaración de abandono}

Para declarar abandono es necesario observar los siguientes aspectos que definen este tipo de declaración.

- Pone en estado de indefensión al individuo

- Vulnera el Derecho Constitucional de acceso a la justicia

- Imposibilidad de iniciar una nueva demanda 
En el anterior Código de Procedimiento Civil, la única consecuencia del abandono era de dar por terminado el proceso, dando la posibilidad a las personas de volver a iniciar una nueva acción que sea de la misma pretensión, garantizando el acceso a la justicia, de tal manera que no existía inconvenientes, porque no contemplaba restricciones a los derechos personales.

El Código Orgánico General de Procesos en su artículo 249 dice:

Efectos del abandono. Declarado el abandono, se cancelarán las providencias preventivas que se hayan ordenado en el proceso. Si se declara el abandono de la primera instancia, no podrá interponerse nueva demanda. Si se declara el abandono en segunda instancia o en el recurso extraordinario de casación, se tendrá por desistida la apelación o dicho recurso y por firme la resolución recurrida.

La consecuencia radica en que afecta a la regresividad cuando uno de los efectos de la actual regulación con el abandono es volver a plantear una nueva demanda, lo que en el Código de Procedimiento Civil en su artículo 387, manifestaba que declarado el abandono se puede volver a iniciar una nueva acción, lo que actualmente violenta el derecho constitucional del acceso a la justicia. (Zavala, 2017).

\section{Repercusiones del Abandono}

Las repercusiones y el abandono de los procesos judiciales se los puede comprender en cinco aspectos según Armijo (2016),

- Pérdida del derecho. La figura del abandono no permite reclamar en otro proceso un derecho que ha sido vulnerado a una persona que acude a la justicia para que el mismo sea resuelto conforme las leyes y la Constitución.

- Transgresión de la Tutela Judicial Efectiva. Conforme lo estipula el Art 75 de la Constitución de la República del Ecuador, es el derecho que todo ciudadano tiene para acceder a la justicia, sin embargo, al declarase abandonando una causa, no permite que se cumplan los principios constitucionales que garantiza a la colectividad un buen desarrollo legal.

- Forma Anormal del Proceso. Debido a que la causa no puede seguirse nuevamente, ni siquiera por impulso del interesado, ya que es una forma tajante y abrupta la terminación del proceso, por no permitir justificación alguna del accionante del porque le impidió cumplir una diligencia procesal como es acudir a la Audiencia, para plantear sus aseveraciones propuestas en su demanda, practicar pruebas y que se pueda resolver su pretensión. (Iñeguez, 2017)

- Incumplimiento de Disposiciones de Tratados Internacionales. Si bien es cierto la Constitución de la República del Ecuador, garantiza la protección de derechos de los ciudadanos, pero con la declaración de Abandono propuesto en el Código Orgánico 
General de Procesos, por inasistencia a las Audiencias no se cumple con lo estipulado en los Tratados Internacionales que no solo su misión es respetar derechos y garantías de la colectividad, sino que no existe límite que para que alguna persona acceda a la justicia, por lo tanto internacionalmente se respalda a las personas hacer uso de su derecho acudir a la justicia cuantas veces requiera y que su causa sea desarrollada lo más eficazmente posible y que el derecho al ser escuchado se convierta en el principal fundamento de su pretensión.

- Afecta el derecho a la Igualdad. Todas las personas somos iguales ante la ley, sin embargo, con la creación del Código Orgánico General de Procesos, Vulnera grandemente este derecho constitucional, consagrado en la Constitución de la República del Ecuador que se encuentra descrito en el artículo 11numeral 2, artículo 11. "El ejercicio de los derechos se regirá por los siguientes principios: Todas las personas son iguales y gozaran de los mismos derechos".

\section{MÉTODO}

La investigación se desarrolló con una metodología de tipo descriptivo-propositivo, bajo un enfoque mixto, cuali-cuantitativo, ya que juntas se complementan. A su vez, el diseño de la investigación fue documental y campo, la primera porque, permitió manejar evidencias que reflejaron con mayor claridad el campo de acción del trabajo investigativo. Y la segunda, porque con la propuesta y aplicación de cuestionarios/guías de entrevista permitió acercarse a las variables del problema y verificar la existencia de esos hechos y fenómenos que justificaran la investigación misma y la propuesta.

Los métodos utilizados durante el desarrollo de la investigación fueron: sistemático, deductivo, inductivo e histórico-lógico:

Sistemático. Se ordenaron los conocimientos de manera coherente, y trabajó en conjunto con el método inductivo y deductivo, de tal forma que al obtener datos y casos respecto del Estado de Excepción, se entenderá sistemáticamente, los parámetros necesarios para su emisión.

Deductivo. Porque se trabajó partiendo desde los datos generales aceptados como válidos para llegar a una conclusión de tipo particular.

Inductivo. Debido a que se trabajó desde los datos particulares para llegar a conclusiones generales.

Histórico- lógico. Porque se analizó la trayectoria concreta de la teoría, su condicionamiento a los diferentes periodos de la historia.

Por otro lado, las técnicas e instrumentos utilizados fueron la observación y la encuesta, siendo el instrumento un cuestionario. 
La población estuvo conformada por 2705, abogados en libre ejercicio de la Provincia de Tungurahua y la muestra fue de 96.

RESULTADOS

Se aplicó el instrumento a los 96 abogados en libre ejercicio de la provincia de Tungurahua. Y se obtuvo como análisis de resultado lo siguiente:

En la Tabla 1 se muestran las consecuencias que produce la inasistencia del actor a las audiencias con el COGEP, se obtuvo que el $60 \%$ de los encuestados manifestaron que se produce desistimiento de la demanda, el $16 \%$ establecen que se origina el allanamiento, y el $24 \%$ opina que se produce el abandono de la acción.

Tabla 1. Consecuencias que producen la inasistencia del actor a una de las audiencias reguladas por el COGEP.

\begin{tabular}{lcc}
\hline \multicolumn{1}{c}{ ALTERNATIVAS } & FRECUENCIAS & PORCENTAJE \\
\hline Desistimiento de la demanda & 58 & $60 \%$ \\
Allanamiento & 15 & $16 \%$ \\
Abandono de la Acción & 23 & $24 \%$ \\
$\quad$ Total & $\mathbf{9 6}$ & $\mathbf{1 0 0 \%}$ \\
\hline
\end{tabular}

La respuesta obtenida demostró que no se encuentra definida, cual es la consecuencia que produce la inasistencia del actor a las audiencias reguladas por el GOGEP, debido a que, con la instauración del sistema oral, en la sustanciación de causas, implica que se están vulnerando derecho constitucional porque la principal consecuencia es el abandono de la acción que impide volver a plantear la acción nuevamente, así lo expresó el artículo 87 del Código Orgánico General de Procesos.

En la Tabla 2 se devela si el abandono por inasistencia a las audiencias reguladas por el COGEP, vulnera los derechos personales del accionante, donde los encuestados respondieron un $72 \%$ que Si, el $9 \%$ No y un $16 \%$ Tal vez.

Tabla 2. La vulneración de los derechos personales del accionante debido al abandono por inasistencia a una de las audiencias reguladas por el COGEP.

\begin{tabular}{lccc}
\hline & ALTERNATIVAS & FRECUENCIAS & PORCENTAJE \\
\hline Si & 72 & $75 \%$ \\
No & 9 & $9 \%$ \\
\multirow{2}{*}{ Tal vez } & & 15 & $16 \%$ \\
& & 96 & $\mathbf{1 0 0 \%}$ \\
\hline
\end{tabular}


Se evidenció con los resultados que sí hay vulneración en los derechos personales del accionante cuando se declara el abandono por inasistencia a las audiencias orales. La Constitución de la República del Ecuador garantiza que los derechos de las personas son de aplicabilidad absoluta, y que cualquier autoridad judicial o administrativa establecerá su cumplimento, indicando que la disposición del COGEP, en lo referente al abandono de la acción contraviene a la normativa constitucional.

En la Tabla 3 se expresa si el abandono por inasistencia a las audiencias reguladas por el COGEP, vulnera los derechos patrimoniales del accionante, donde los encuestados manifestaron que, un $58 \%$ que $\mathrm{Si}$, el $22 \%$ No y un $20 \%$ Tal vez.

Tabla 3. El abandono por la falta de concurrencia a las audiencias reguladas por el COGEP, ecuatoriano vulnera los derechos patrimoniales del accionante.

\begin{tabular}{lccc}
\hline & ALTERNATIVAS & FRECUENCIAS & PORCENTAJE \\
\hline Si & 56 & $58 \%$ \\
No & & 21 & $22 \%$ \\
\multirow{2}{*}{ Tal vez } & & 19 & $20 \%$ \\
& & 96 & $\mathbf{1 0 0 \%}$ \\
\hline
\end{tabular}

En la Tabla 3 se expresa si el abandono por inasistencia a las audiencias reguladas por el COGEP, vulnera los derechos patrimoniales del accionante, donde los encuestados manifestaron que, un $58 \%$ que $\mathrm{Si}$, el $22 \%$ No y un $20 \%$ Tal vez.

En la Tabla 4, reflejan los motivos por el cual COGEP se ha establecido que la inasistencia a una de las audiencias ocasiona el abandono. El 57\% de los encuestados indicaron que no existen causas rezagadas, el $27 \%$ opinaron que es la responsabilidad del defensor técnico del actor, y el $16 \%$ la celeridad procesal.

Tabla 4. Motivo por el cual en el COGEP se ha establecido que la inasistencia a una de las audiencias ocasiona el abandono.

\begin{tabular}{|c|c|c|}
\hline ALTERNATIVAS & FRECUENCIAS & PORCENTAJE \\
\hline Que no exista causas rezagadas & 55 & $57 \%$ \\
\hline Responsabilidad del defensor técnico del actor & 26 & $27 \%$ \\
\hline Celeridad Procesal & 15 & $16 \%$ \\
\hline Total & 96 & $100 \%$ \\
\hline
\end{tabular}

De esta manera, se evidenció que la mayoría de profesionales del derecho a quienes se les realizó la encuesta, mencionaron que se declara el abandono de la acción para que no existan causa rezagadas, o lentas, pero es muy drástico la manera como se declara el abandono de la acción, sin justificación alguna de la persona que no pudo excluir a dicha diligencia no más 
que decir que se choca con la norma constitucional en lo estipulado en el artículo 76 numeral 7 literal c, y g, ya que ni el patrocinador puede intervenir con alguna alegación a favor de su defendido.

La Tabla 5 refleja si el abandono por inasistencia a las audiencias normadas por el COGEP, vulnera el acceso a la justicia, los encuestados indican un $89 \%$ que Sí y el $11 \%$ que No.

Tabla 5. El abandono por inasistencia a una de las audiencias normadas por el COGEP, vulnera el acceso a la justicia.

\begin{tabular}{lccc}
\hline & ALTERNATIVAS & FRECUENCIAS & PORCENTAJE \\
\hline Si & & 84 & $89 \%$ \\
No & & 12 & $11 \%$ \\
& & 96 & $\mathbf{1 0 0 \%}$ \\
\hline
\end{tabular}

Se evidenció que, si hay vulneración en el acceso a la justicia, debido a que el accionante se encuentra limitado de volver a interponer la misma acción, y al no poder introducir nuevamente la acción inclusive afecta el derecho a la igualdad contemplado en el artículo 11, numeral 2, porque en este caso el demandado el que está obligado a responder por una obligación se vería favorecido al declararse el abandono, ya no existe presión alguna para que responda por la causa seguida en su contra.

En la Tabla 6, se muestra si debería derogarse la normativa establecida por el COGEP, sobre los efectos que produce el abandono por inasistencia a las audiencias orales. Los encuestados han manifestado que Si un $68 \%$, No un $17 \%$ y un Tal vez $16 \%$.

Tabla 6. Debería derogarse la normativa establecida por el COGEP sobre los efectos que produce el abandono por inasistencia a las audiencias orales.

\begin{tabular}{lccc}
\hline & ALTERNATIVAS & FRECUENCIAS & PORCENTAJE \\
\hline Si & 65 & $68 \%$ \\
No & & 16 & $17 \%$ \\
\multirow{2}{*}{ Tal vez } & & 15 & $16 \%$ \\
& & $\mathbf{9 6}$ & $\mathbf{1 0 0 \%}$ \\
\hline
\end{tabular}

Así que, se demostró que los profesionales a quienes se les realizó la consulta indicaron en su mayoría que si debería derogarse la normativa establecida por el COPEG, en lo que refiere al abandono por inasistencia a las audiencias, debido a que se debe entender que los derechos constitucionales son de supremacía sobre cualquier ley, inclusive se encuentran establecidos en los tratados internacionales de derechos humanos, si una persona acude a la justicia espera 
una resolución eficaz, pero si al acceder a reclamar un derecho vulnerado y el mismo por declaratoria de abandono no permite seguir la acción, produce un desorden jurídico, en la sociedad.

En la Tabla 7 se refleja que los encuestados respondieron un $80 \%$ que Sí, un $16 \%$ que No, y un 4\% Tal vez, se garantizará los derechos personales del accionante con la elaboración del anteproyecto de ley reformatoria al COGEP, respecto a la normativa que regula el abandono por inasistencia a las audiencias.

Tabla 7. La elaboración del anteproyecto de ley reformatoria al COGEP, respecto a la normativa que regula el abandono por inasistencia a las audiencias se garantizará los derechos personales del accionante.

\begin{tabular}{lccc}
\hline & ALTERNATIVAS & FRECUENCIAS & PORCENTAJE \\
\hline Si & 65 & $68 \%$ \\
No & & 16 & $17 \%$ \\
\multirow{2}{*}{ Tal vez } & & 15 & $16 \%$ \\
& & 96 & $\mathbf{1 0 0 \%}$ \\
\hline
\end{tabular}

En este orden de ideas, se demostró que la mayoría de profesionales encuestados han respondido que, si es necesario un Anteproyecto de ley reformatoria al COGEP, en lo concerniente a la normativa de regulación de abandono por inasistencias, pues es muy razonable la modificación, ya que garantizará el respeto a los derechos personales del accionante, que se encuentran establecidos en el artículo 66 de la Constitución de la República del Ecuador, y que son de supremacía sobre cualquier ley.

En la Tabla 8, se muestra que los encuestados respondieron que Si, un $68 \%$, No, un $13 \%$ y un 19\% Tal vez, se garantizará los derechos patrimoniales del accionante con la elaboración del anteproyecto de ley reformatoria al COGEP, respecto a la normativa que regula el abandono por inasistencia a las audiencias.

Tabla 8. La elaboración del Anteproyecto de ley reformatoria al COGEP, aspecto a la normativa que regula el Abandono por inasistencia a las audiencias se garantizará los derechos patrimoniales del accionante.

\begin{tabular}{lccc}
\hline & ALTERNATIVAS & FRECUENCIAS & PORCENTAJE \\
\hline Si & 65 & $68 \%$ \\
No & & 13 & $13 \%$ \\
\multirow{2}{*}{ Tal vez } & & 18 & $19 \%$ \\
& Total & 96 & $\mathbf{1 0 0 \%}$ \\
\hline
\end{tabular}


Por lo tanto, se demostró que los profesionales encuestados indicaron que sí es necesario un Anteproyecto de ley reformatoria al COGEP, en lo concerniente a la normativa de regulación de abandono por inasistencias, pues es como se ha manifestado anteriormente, al acudir un ciudadano a la justicia, lo hace porque sus derechos no fueron respetados y de alguna manera al seguir una acción se garantizara su cumplimiento, y en lo que menciona a los derechos patrimoniales se debe tomar en cuenta que el patrimonio de una persona incluye muchos factores entre ellos la supervivencia económica que lo garantiza la Construcción

Cabe destacar que es de suma importancia realizar la propuesta de elaboración del Anteproyecto de ley reformatoria al COGEP, en lo concerniente a la normativa de regulación de abandono por inasistencias para así poder darle una solución al problema de la investigación.

\section{Propuesta Anteproyecto de ley reformatoria al COGEP, sobre la declaratoria de abandono de las audiencias para garantizar los derechos personales y patrimoniales del accionante}

\section{Objetivo}

Elaborar un Anteproyecto de ley reformatoria al COGEP, sobre la declaratoria de abandono a las audiencias para garantizar los derechos personales y patrimoniales del accionante.

\section{Justificación}

A través del Anteproyecto de la ley reformatoria al COGEP, sobre la declaratoria de abandono a las audiencias para garantizar los derechos personales y patrimoniales del accionante. Es la solución para la colectividad quien se vería beneficiada, en virtud de que al proponer una acción legal, las personas hagan uso de ese derecho pero que el mismo sea garantizado que así como se ha iniciado una causa, le permita que llegue hasta su resolución y que en ningún momento se declare el abandono por insistencias a las audiencias en el sistema procesal oral, si bien es cierto toda persona tiene la potestad de acudir a los órganos jurisdiccionales y proponer la acción de la cual se crea asistida , sin embargo el Código Orgánico General de Procesos, en su artículo 87, establece que una vez que no se acuda a las audiencia se declararía el abandono de la acción, sin poder volver a proponerla, de una manera radical que no permite al accionante una mínima justificación de su inasistencia y que pueda proseguir el trámite legal iniciado, y por ello se está vulnerando las garantías constitucionales.

\section{Desarrollo de la propuesta}

El Ecuador se ha caracterizado por su estado constitucional que garantiza los derechos de los ciudadanos así lo establece en su artículo 1, "los derechos se podrán ejercer, promover y exigir de forma individual o colectiva ante las autoridades competentes; estas autoridades garantizarán su cumplimiento" (Constitución de la República del Ecuador, 2008). 
Al establecerse que los ecuatorianos tienen beneficios, en este caso, están protegidos legalmente, por lo tanto, las autoridades competentes deben aplicar justicia y velar por su respeto.

Se debe indicar que, de manera individual, una persona puede exigir que se respeten sus derechos proponiendo una acción legal, sin embargo desde la creación del Código Orgánico General de Procesos, al instaurar un sistema procesal oral, se proyecta a que se reduzca el tiempo en la tramitación de las causas, pero en ningún momento se analizó, que en las fases del procedimiento, siendo la audiencia un mecanismo donde se desarrolla propiamente por medio de este sistema oral todo el proceso, al tipificar en el artículo 87, que se declare el abandono de la acción por la inasistencia a la audiencia, sin poder volver a plantearla, afecta gravemente los derechos tanto personales como patrimoniales del accionante.

Si se toma en cuenta lo que dispone el artículo 75 de la Constitución de la República del Ecuador que plantea:

Toda persona tiene derecho al acceso gratuito a la justicia y a la tutela efectiva, imparcial y expedita de sus derechos e intereses, con sujeción a los principios de inmediación y celeridad; en ningún caso quedará en indefensión. El incumplimiento de las resoluciones judiciales será sancionado por la ley.

Cuando un ciudadano propone una acción está ejerciendo su derecho personal ante la justicia para que al reclamar el mismo se dé solución, y utiliza no solo ese beneficio para hacer cumplir el deber del Estado, sino que al acudir ante la Justicia, por medio de las autoridades competentes, no solo reclama un derecho individual sino que el momento que se inicia una acción, también los derechos patrimoniales cabe dentro de ello, si bien es cierto el acceso a la justicia es gratuito pero la tramitación de las causas requiere estimación pecuniaria, refiriendo a los derechos patrimoniales.

Cuando se produce el abandono de una acción legal, no solo el derecho personal se ve afectado sino el patrimonial, porque de una u otra manera, el accionante acude por solucionar un derecho violentado.

Definidamente, con la ley reformatoria al Código Orgánico General Procesos, protegerá a las personas que no se transgredan sus garantías, que el momento de inasistencias a las audiencias orales se permita justificar los motivos de los cuales provocaron, y que pueda seguir su acción sin que se vea afectados sus derechos personales y patrimoniales garantizados por la carta magna en artículos 76 y 169 que refiere al debido proceso. 


\section{LEY REFORMATORIA AL CODIGO ORGANICO GENERAL DE PROCESOS.}

Art.1.- En el articulo 87, sustituyase el numeral 1 por el giguiente:

Cuando quien presentó la demanda o solicitud no comparece a la audiencia correspondiente, deberá justificar su inasistencia en un término de cinco dias, de encontrarse fundamentada la inasistencia la o el Juez ser̃alará nuevo día y hora para la práctica de la audiencia.

En caso de Inasistencia injustificada a la audiencia dentro del término concedido, se ordenará el archivo del proceso, sin que se declare el abandono.

\section{DISPOSICIÓN FINAL}

La presente ley reformatoria entrará en vigencia a partir de su promulgación en el Registro Oficial.

Dada y suscrita en la sede de la Asamblea Nacional ubicada en el Distrito Metropolitano de San Francisco de Quito, provincia de Pichincha, a los ... dias del mes de ... del 2018

\section{DR. JOSÉ RICARDO SERRANO SALGADO}

Presidente

\section{DRA. LIBIA RIVAS ORDOÑEZ}

\section{Secretaria General}

Figura 1. Ley reformatoria al COGEP

\section{CONCLUSIONES}

La investigación posterior a la aplicación del instrumento de recolección de datos, se llegó a las siguientes conclusiones: la instauración oral del Código Orgánico General de Procesos COGEP, en lo refiere a la tramitación ha portado al avance legal en Ecuador.

Sin embargo, al producirse el abandono de la acción por la inasistencia a las audiencias no se respetó la garantía normativa, de ser escuchado debido a que se archiva la causa sin que el accionante de opinión alguna. Por lo tanto, al establecer el artículo 87 del Código Orgánico General de Procesos, que se declarará el abandono, solo por inasistencia a las audiencias, ni siquiera el Defensor podrá intervenir por lo que se estaría vulnerando el derecho a la defensa. 
A su vez, en el sistema Oral, en las audiencias permiten la aportación de las pruebas necesarias para la defensa de las partes, de modo que los intervinientes tengan certeza de que el Juez tuvo apreciación de las mismas.

En lo referente a los derechos personales del accionante, lo establece el artículo 66 de la Constitución de la República del Ecuador, del cual establece un goce de los mismos que al declarase el abandono de la acción los mismos se verían afectados al ya no poder reclamarlos.

En este sentido, el abandono de la acción impide al acreedor poder hacer uso de su derecho patrimonial, pues el obligado se vería beneficiado y no pagaría su obligación, generando un enriquecimiento ilícito.

Para finalizar, el beneficio del Anteproyecto de ley reformatoria al COGEP, sobre la declaratoria de abandono a las audiencias garantizará los derechos personales y patrimoniales del accionante, garantizados constitucionalmente.

\section{REFERENCIAS}

Alessandri, A. (1950). Revolución de 1891. Santiago de Chile: Nascimiento

Armijos, C. (2016). La Declaración de Abandono Procesal en materia no penal, sin permitir justificación alguna del accionante vulnera el derecho constitucional a la defensa. Loja, Loja, Ecuador

Asamblea Nacional del Ecuador (2015). Código Orgánico General de Procesos. (RO-S 506: 22 de mayo de 2015)

Barrando, E., y Odete, A. (2013). El concepto impunidad, su abordaje en los Institutos de Derecho Internacional de los Derechos Humanos, Derecho Internacional Humanitario y Derecho Penal Internacional. Madrid: Universidad Carlos II de Madrid

Casanueva, S. (2014). Juicio Oral Teoría y Práctica

Constituyente, A. (2008). Constitución de la República del Ecuador. Quito

Congreso Nacional del Ecuador (2005). Codificación del Código de Procedimiento Civil. (Cod. 2005-11. RO-S 58: 12 de junio de 2005)

Coronado, W. (2008). La efectiva aplicación en el principio de inmediación en la producción de la prueba en el procedimiento civil oral. Maracaibo, Venezuela

Dal Ri, L. (2016). A Tradição Romanística em Período Medieval: entre práxis e esquecimento. Sequência (Florianópolis), 269-294

Fernández, F. (1993). El Nuevo Ordenamiento Constitucional Perú. Lima
Fonrouge, M. (1996). Las Audiencias Públicas

Iñeguez, M. (2017). Efectos Jurídicos del Abandono del Proceso previsto en el Código Orgánico General de Procesos. Cuenca, Azuay, Ecuador

Maurino, L. (1991). Perención de la instancia en el proceso Civil. Astrea, Bs

Mejía, A. (2017). Evolución Histórica de la Oralidad y la Escritura en el Proceso Civil Español y Ecuatoriano. Revista de Derecho, 73-94

Nieva, J. (2010). Los problemas de la oralidad. Revista del Ministerio Público, 257

Núñez, R. (2005). Crónica sobre la Reforma del Sistema Procesal Civil Chileno. Revista de Estudios de la Justicia, 189

Ossorio, M. (2006). Diccionario de Ciencias Jurídicas y Políticas. Buenos Aires: Heliasta S.R.L

Rodríguez, I. (2010). La prueba en la oralidad civil en Colombia. Medellín

Torres, D. (2014). Los medios de impugnación ante el proceso y el procedimiento contemporáneo. Foro Revista De Derecho, 121-149

Zabaleta, Y. (2017). La contradicción en materia probatoria, en el marco del proceso penal colombiano. CES Derecho, 172-190

Zavala, X. (2017). Abandono del proceso en el Código Orgánico General de Procesos, conflicto de principios y violación de Derechos Constitucionales. Quito, Ecuador 